\title{
BENJAMIN MOSER: QUANDO A LUZ DOS HOLOFOTES INTERESSA MAIS QUE A ÉTICA ACADÊMICA
}

\section{BENJAMIN MOSER: WHEN THE SPOTLIGHTS CONCERN MORE THAN ACADEMICAL ETHICS}

Thiago Cavalcante Jeronimo

RESUMO: Este artigo põe luz a alguns temas tratados por Benjamin Moser, que podem ser questionados tanto pela análise de excertos da biografia que o autor escreveu, Clarice, (lê-se "Clarice vírgula"), quanto pela organização e introdução que fez para Todos os contos, de Clarice Lispector, e, ainda, pelas entrevistas que concedeu no tocante ao tom desrespeitoso que direciona à Academia e às pesquisas brasileiras acerca da autora. Este estudo é alicerçado, sobretudo, nas contribuições de Benjamin Abdala Junior concernentes às "coincidências" e aos "equívocos" enxergados pelo crítico na biografia escrita por Moser; na pesquisa de Berta Waldman acerca da não pretensão de enquadrar a escrita clariciana em um "gueto literário", seja o judaico ou o cristão; nas análises de Nádia Battella Gotlib em relação à infundamentada afirmação que Moser faz sobre a doença de Marieta, mãe de Clarice Lispector, e no posicionamento crítico de Eneida Maria de Souza, estudiosa do gênero literário biográfico.

PALAVRAS-CHAVE: Clarice Lispector. Biografia. Ficção biográfica. Biografia literária.

ABSTRACT: This article sheds light on some of the themes dealt with by Benjamin Moser, that can be questioned both by analyzing excerpts from the biography the author wrote, Clarice, (read "Clarice comma"), and by the organization and introduction he made for Todos os contos (Short Stories Anthology), by Clarice Lispector, and also by the interviews she gave regarding the disrespectful tone that directs the Academy and the Brazilian research about the author. This study is based, above all, on the contributions of Benjamin Abdala Junior concerning the "coincidences" and "misconceptions" seen by the critic in the biography written by Moser; in Berta Waldman's research on the non-pretension of framing Clarecian writing in a "literary ghetto", whether Jewish or Christian; in Nádia Battella Gotlib's analysis of Moser's unsubstantiated statement about Marieta's disease, mother of Clarice Lispector, and in the critical position of Eneida Maria de Souza, a scholar of the biographical literary genre.

KEYWORDS: Clarice Lispector. Biography. Biographical fiction. Literary biography.

i Universidade Presbiteriana Mackenzie (UPM-SP). E-mail: thiagocavalcante@live.com. 
As biografias são como a interpretação de uma peça musical. As pessoas confiam muito no retrato, mas é apenas uma maneira de contar, é a minha forma, minha história, e não a própria pessoa. Benjamin Moser

Lançada em 16 de novembro de 2009 pela extinta Cosac Naify, a biografia escrita por Benjamin Moser (1976), Clarice, uma biografia (lê-se "Clarice vírgula") é prenúncio de conflitos, equívocos, inesperadas coincidências e apropriações indevidas de trabalhos de ilustres pesquisadores brasileiros pelo crítico norte-americano.

Ao longo dos oitos anos da publicação de Clarice,, cresce o número de suas edições e, de maneira ainda maior, os desdobramentos das incoerências apregoadas por Benjamin Moser. Busca-se neste ensaio trazer para discussão algumas informações oferecidas de modo leviano por Moser, seja por intermédio da biografia que o autor escreveu acerca da autora de $A$ hora da estrela; seja pelo arranjo inconsistente da coletânea Todos os contos, de Clarice Lispector, que contempla além de contos, anunciados no título, crônicas e texto dramático; seja também por entrevistas que o biógrafo concedeu a respeito do seu posicionamento no tocante à Academia (pesquisadores, professores, críticos) e à cultura brasileira ${ }^{1}$.

No texto crítico intitulado "Biografia de Clarice, por Benjamin Moser: coincidências e equívocos", publicado por Benjamin Abdala Junior em 2010, isto é, há poucos meses do lançamento da biografia escrita por Moser, o literato sintetiza os procedimentos do biógrafo concernentes ao título de seu ensaio, "coincidências e equívocos", apontando inclusive apropriações explícitas das pesquisas de Nádia Battella Gotlib e Teresa Montero.

Logo no primeiro capítulo, Moser recorre à passagem de Clarice pelo Egito e as visões da escritora por diferentes personalidades, para concluir que ela permanece como enigma. É essa a proposta do primeiro capítulo do livro de Nádia Gotlib [Clarice, uma vida que se conta], que aponta para várias visões de Clarice - "pela empregada, pela vizinha, pelos parentes, amigos, jornalistas, críticos, escritores",

\footnotetext{
${ }^{1}$ Registre-se a reflexão de Anna Caballé, professora de literatura espanhola na Universidade de Barcelona, quando do lançamento da biografia de Moser na Espanha: "A Moser pues Brasil no le interesa y ofrece una visión poco amable, casi despectiva, del país: habla del declive de sus grandes ciudades sin una palabra grata sobre ellas; de Recife -la ciudad que funda el hondo sentimiento brasileño de Lispector- solo le importa el barrio judío de Boa Vista donde vive la familia al poco de llegar. Por no hablar de los años finales en Rio de Janeiro: la ciudad, el entorno, apenas existe" (CABALLÉ, 2017, s/p).
} 
para concluir que... Clarice permanece como enigma. Ao longo dos capítulos, uma estrutura semelhante: capítulos curtos, com sugestivos, que percorrem praticamente, na sua grande maioria, os mesmos textos. Aliás, parte desses textos foi também utilizada por Teresa Montero, no seu livro de 1999 [Clarice Lispector: eu sou uma pergunta], em que ela abre novas frentes de leitura de dados biográficos, como, por exemplo, as provenientes da descoberta de processos de naturalização depositados no Arquivo Nacional (ABDALA JUNIOR, 2010, p. 286-287).

As semelhanças não se restringem apenas à estruturação narrativa da biografia escrita por Moser. Abdala Junior esclarece que:

Se no livro de Nádia Gotlib há um subcapítulo intitulado "As receitas da bruxa", no de Moser há capítulo intitulado "A bruxa". No da crítica brasileira há "Os diálogos possíveis", no de Moser há "Diálogos possíveis". Em Clarice, uma vida que se conta há "O furacão Clarice", em Clarice, "Furacão Clarice"... (ABDALA JUNIOR, 2010, p. 287).

É materializado, dessa forma, um primeiro enfoque reflexivo e crítico da Academia acerca da produção conflituosa de Moser no que condiz à vida e à obra de Clarice Lispector, desdobrando, inclusive, as questões judaicas e de violência sexual que o biógrafo enfatiza em sua narração.

O judaísmo em Clarice Lispector, na perspectiva de Benjamin Moser, é uma pontuação que se avulta a partir da abertura de sua Clarice,. Seu autor o apresenta como fio estruturador de toda produção escritural da escritora. Para o norte-americano, Clarice não só foi influenciada pela tradição judaica, como nutriu diálogo constante com a religião e os costumes de seus antepassados. Segundo Moser, a escritora é judia não apenas por ter nascido na Ucrânia, mas por íntima aproximação para com a religião, quer nos seus textos, quer nas suas vivências: "Em Clarice, uma biografia, examinei as raízes da autora no misticismo judaico e o impulso essencialmente espiritual que anima sua obra" (MOSER, 2016, p. 21).

Rotular Clarice como escritora judia, cabe enfatizar, não condiz, integralmente, nem com as vivências da autora, nem com sua vontade de pertencimento:

Sou judia, você sabe. Mas não acredito nessa besteira de judeu ser o povo eleito de Deus. Não é coisa nenhuma. Os alemães é que devem ser, porque fizeram o que fizeram. Que grande eleição foi essa, para 
os judeus? Eu, enfim, sou brasileira, pronto e ponto (LISPECTOR apud COUTINHO, 1980, p. 165-170).

Abre-se reflexão ao modo crítico e pertinente que a pesquisadora e professora de literatura israelense e judaica, Berta Waldman, faz acerca dos aspectos judaicos sinalizados na obra de Clarice Lispector, no entanto, sem a pretensão de enquadrá-la nos estereótipos de escritora judia. O livro Entre passos e rastros: presença judaica na literatura contemporânea brasileira é exemplo dessa percepção dialógica de reflexão e refratamento, produção que conflui contrariamente às interpretativas de Moser. Esclarece a pesquisadora:

\footnotetext{
Meu intento não é o de transformar Clarice Lispector em escritora étnica, circunscrevendo seu texto a uma espécie de gueto literário, mas sim o de estudar o costado judaico de sua ficção como uma expressão da cultura brasileira, que conta com a participação histórica dos judeus em sua expansão pelo continente americano (WALDMAN, 2003, p. 18, grifo da autora).
}

Berta Waldman ilumina o diálogo judaico existente na tessitura narrativa de Clarice, mas o configura como "água viva", isto é, reconhece o ousado projeto escritural da autora que rompe com estigmas e nomenclaturas, não sendo aprisionada em guetos literários ou em estruturas normativas. É válido marcar que a personagem Macabéa consulta uma cartomante para aliviar sua dor de existir, os livros $A$ paixão segundo G. $H$. e $A$ via crucis do corpo, remetem, já explícitos nos seus títulos, a um diálogo com o cristianismo, e a entrevistadora Clarice Lispector, em "diálogo possível” com o pintor argentino, naturalizado brasileiro, Carybé, menciona que "Exu é seu amigo do peito e que lhe ajudará em tudo": "Exu é poderoso" (LISPECTOR, 2007, p. 218).

Voltando atenção ao ensaio de Benjamin Abdala Junior, o crítico esclarece que ao privilegiar a ascendência judaica de Clarice Lispector, "[Moser] recai numa linha de reflexão que desloca seu centro de interesse e, na ânsia de reconstituir um passado de dimensão épica, resvala em riscos de argumentação, que acabam prejudicando o seu fio de exposição" (ABDALA JUNIOR, 2010, p. 288).

Esses riscos de argumentação, sobretudo, são a recriação de cenas da vida da família Lispector consoantes ao estupro delegado à mãe de Clarice, sem comprovação pelo biógrafo. Moser ficcionaliza o passado da família 
Lispector no seu Clarice,: "Com certeza absoluta, o autor identifica o crime (estupro), o criminoso (bolcheviques russos) e o diagnóstico de doença "proveniente" desse crime (sífilis)" (ABDALA JUNIOR, 2010, p. 288). Cabe a redundância: sem comprovar essas afirmativas.

Sublinhe-se o posicionamento da escritora Nélida Piñon, amiga pessoal de Clarice Lispector, acerca dos equívocos instaurados na biografia de Benjamin Moser:

Após sua morte [morte de Clarice Lispector], recusei-me durante anos a prestar testemunho sobre ela, embora constate os equívocos biográficos cometidos sobre esta genial escritora. Particularmente relativos à mãe que, segundo versão [...] do biógrafo Benjamin Moser, teria sido violada, deste ato brutal advindo a terrível doença que a levou à morte quando Clarice tinha 9 anos de idade, já instalados no Recife. Um fato que me inquieta, desejosa de saber através de quem obteve ele tal dramática confidência. Acaso de Elisa Lispector, escritora de talento, falecida no ano de 1989, a quem conheci? Uma mulher severa, circunspeta e que terá sofrido por não the haverem reconhecido o talento que se julgava concentrado na irmã caçula. Incapaz ela, a meu juízo, de transbordamento, de ceder intimidade a quem fosse. E menos ainda deixar alguma pista que revelasse afinal o segredo dolorido da família. Ou se originou de Tânia, que morreu em 2007, com a idade de 92 anos? De todos os modos, estranho que alguém da família afinal tenha exposto ao público uma possível verdade resguardada durante décadas (PIÑON, 2012, p. 71-72).

A ficcionalização biográfica pontuada por Moser, de forma reticente para depois firmar-se como ocorrência verídica em seu livro, reaparece sem sombra de dúvidas não prefácio que o autor escreveu à compilação Todos os contos, de Clarice Lispector, lançada pela editora Rocco, em 2016. Assevera o autor: "Sua mãe foi violentada" (MOSER, 2016, p. 18, grifo nosso). Uma suposição interpretativa torna-se ocorrência "comprovada sem provas" pelo biógrafo-queficcionaliza.

Acrescente-se ainda o posicionamento de Nádia Battella Gotlib, contrapelo às afirmativas de Benjamin Moser. Ao organizar o livro memorialístico e póstumo de Elisa Lispector, Retratos antigos, a pesquisadora esclarece que:

[...] nesse texto aparece a explicitação da doença da mãe: "hemiplegia", ou seja, paralisia parcial do corpo proveniente de trauma. [...] violência causada por bolcheviques durante um pogrom. A hemiplegia - paralisia de metade do corpo que afeta justamente a 
parte contrária à parte do cérebro afetada pelo trauma ou golpe manifesta-se já na viagem de exílio e seria paulatinamente agravada, a ponto de já, em Recife, a mãe não mais poder caminhar, tendo de passar o dia, permanentemente, numa cadeira de rodas (GOTLIB, 2012, p. 63, grifos nossos).

Destaca-se o esclarecimento apresentado pela biógrafa: "violência causada por bolcheviques", isto é, o pogrom interpretado como ato de violência e não como ato de violentar. Ainda segundo a autora de Clarice, uma vida que se conta (1995), uma segunda menção da doença da mãe das escritoras é materializada por Elisa Lispector no livro $O$ tigre de bengala, publicado em 1985. O texto "refere-se aos tremores do corpo causados pelo mal de Parkinson. Seria esse o segundo de apenas dois diagnósticos, que se conhecem da doença da mãe, além, naturalmente, do atestado de óbito ${ }^{2}$, que atesta morte por "congestão edematose (sic) no curso de tuberculose" (GOTLIB, 2012, p. 67).

Ao recordar de sua mãe, Elisa escreveu que: "A hemiplegia de que a mãe fora acometida numa fatídica noite de pogrom progredindo devagar, mas insidiosamente" (LISPECTOR, 2012, p. 111). Cabe, também, a citação da escritora no romance em que ficcionaliza a saga da família Lispector em direção ao Brasil, No exílio. A personagem Marim (a mãe), para proteger seus filhos e vizinhos que se refugiaram em sua casa à fuga de pogroms, sai à rua na tentativa de conter os ataques milicianos:

\begin{abstract}
Quando deu acordo de si, estava na rua, de cabelos ao vento, a neve quase a atingir-lhe a cintura. Ao avistar dois milicianos vindo em sua direção, caiu-lhes aos pés, pedindo auxílio. Depois as imagens embaralharam-se fantasticamente à luz baça do luar. Como num sonho, por entre espessa neblina, viu homens correndo e travando renhido tiroteio, e corpos tombando e sendo amortalhados pela neve. Em seguida, por um tempo que lhe pareceu interminável, o mundo ficou deserto. Então, encaminhou-se para casa a passos vagarosos e elásticos, só perceptíveis pelo crepitar cantante da neve (LISPECTOR, 2005, p. 35).
\end{abstract}

\footnotetext{
2 "Certidão de óbito de Marieta Lispector, falecida em 21 de setembro de 1930 no Hospital Oswaldo Cruz, em Recife, com 41 anos de idade, na época residindo à Rua Imperatriz n. 173, $2^{\circ}$ andar. A doença de Marieta Lispector, causada por degenerescência do sistema neurológico, foi se agravando ao longo dos anos, a ponto de perder os movimentos e usar cadeira de rodas" (GOTLIB, 2009b, p. 78).
} 
Como explicitado no excerto, não há nessa narrativa indício de violência sexual direcionados à mãe das escritoras, e, mesmo se houvesse, não seria próprio, em crítica literária (e numa biografia que prime por apresentar as informações do biografado de forma coerente), tratar do texto ficcional como verdade empírica. A ficção é representação do real, não o real, como já observado pelo crítico alemão Erich Auerbach, em 1953. Nesse veio, a "leitura dos textos de Clarice [ou de Elisa] sem a consideração de que textos de memória [e de ficção] são também construção do imaginário, e assim considerados, não se apresentam mais como provas de um território eminentemente factual" (ABDALA JUNIOR, 2010, p. 292).

O posicionamento de Benjamin Abdala Junior recupera o que a pesquisadora e crítica do gênero biográfico Eneida Maria de Souza enfatiza no seu estudo intitulado "Biografia, um bem de arquivo". Para a crítica

\begin{abstract}
Ainda que determinada cena recriada na fiç̧ão remeta a um fato vivenciado pelo autor, é preciso distinguir entre a busca de provas e a confirmação de verdades atribuídas ao acontecimento, de modo como a situação foi metaforizada e deslocada pela ficção. O nome próprio de um personagem, mesmo que se refira a pessoas conhecidas do escritor, nada impede que sua encenação embaralhe as referências e coloque a verdade biográfica em suspenso (SOUZA, 2008, p. 124, grifos nossos).
\end{abstract}

Compete elucidar a constatação da biógrafa Nádia Battella Gotlib no tocante ao "pacto ficcional" que Clarice Lispector cria com seu leitor, a exemplo o conto Felicidade clandestina. A voz narrativa "intui ser" a da autora recordando cenas de sua infância no Recife. Em menina, Clarice viveu na cidade nordestina. Ocorrência que trará resquícios, é bem verdade, na produção ficcional e cronista da autora. O conto, logo na sua abertura, descreve a filha do dono da livraria como: "[..] gorda, baixa, sardenta e de cabelos excessivamente crespos, meio arruivados" (LISPECTOR, 1998, p. 9).

No seu livro Clarice fotobiografia, Gotlib recupera cerca de oitocentas fotos para compor um registro inédito e de abalizada fortuna documental no que tange à reconstrução da vida de Clarice Lispector através de imagens. A pesquisadora, dentre as imagens selecionadas, recupera uma foto de Rebeca Berenstein, "a filha do dono da livraria que inspirou a criação da personagem do conto 'Felicidade clandestina"' (GOTLIB, 2009b, p. 92). Ora, a imagem se 
contrapõe ao texto narrado ${ }^{3}$ : Rebeca não era gorda, nem baixa, nem sardenta e não tinha os cabelos excessivamente crespos.

Voltando atenção às questões suscitadas pela obra Clarice, a "narrativa imaginária" de Benjamin Moser apresenta, ainda, uma interpretação descuidada ao presentificar via escrita a foto de Clarice Lispector ao lado da também escritora Carolina Maria de Jesus. Um registro que reflete uma face preconceituosa do autor e que lhe acarretou, segundo matéria divulgada pela revista CULT, acusações de desprestígio e racismo em relação à Carolina. Materializada no site oficial da revista, a notícia é enfática em sua manchete: "Escritor é acusado por racismo em trecho de biografia de Clarice Lispector". Segue o fragmento transposto da edição de Clarice, veiculada pela Cosac Naify:

Numa foto, ela [Clarice] aparece em pé, ao lado de Carolina Maria de Jesus, negra que escreveu um angustiante livro de memórias da pobreza brasileira, Quarto de despejo, uma das revelações literárias de 1960. Ao lado da proverbialmente linda Clarice, com a roupa sob medida e os grandes óculos que a faziam parecer uma estrela de cinema, Carolina parece tensa e fora do lugar, como se alguém tivesse arrastado a empregada doméstica de Clarice para dentro do quadro (MOSER, 2009, p. 22). ${ }^{4}$

33 Compete mencionar a crônica "Esclarecimentos - explicação de uma vez por todas", publicada por Clarice Lispector em 14 de novembro de 1970, no Jornal do Brasil, como exemplo de encenação escritural da autora, ou seja, dependendo do seu enunciatário ou da circunstância experienciada, Clarice manifestava uma data diferente do seu registro de nascimento. Neste texto jornalístico, de marcas autobiográficas, a cronista diz que chegou ao Brasil com "apenas dois meses de idade" (LISPECTOR, 1999, p. 320, grifo da autora). Informação posta em suspenso nas pesquisas de Nádia Battella Gotlib. A biógrafa, em um trabalho de vasta sondagem das datas de nascimentos apresentadas por Clarice e por documentos oficiais, esclarece que quando chegou ao Brasil a autora“[...] tinha um ano e três meses: era março de 1922" (GOTLIB, 2009, p. 46), sendo "10 de dezembro de 1920 [...] a data que consta na certidão original [de nascimento de Clarice] expedida na Ucrânia" (GOTLIB, 2009, p. 34).

${ }^{4}$ A biografia Clarice, tem sido divulgada pelo selo da Companhia das Letras após o fechamento da Cosac Naify. Seu relançamento por essa nova editora marca alteração no texto aqui pontuado com a seguinte materialidade: "Numa foto, Clarice aparece em pé, ao lado de Carolina Maria de Jesus, que escreveu um angustiante livro de memórias da pobreza brasileira, Quarto de despejo, uma das revelações literárias de 1960, que transformou sua autora numa das raríssimas negras a alcançar sucesso literário naquela época. Numa sociedade ainda sofrendo sob a herança de quase 400 anos de escravidão, onde a cor da pele estava fortemente vinculada à classe social, poucos adivinhariam que a loira Clarice, com a roupa sob medida e os grandes óculos escuros que a faziam parecer uma estrela de cinema, tivesse origens ainda mais miseráveis que as de Carolina" (MOSER, 2017, p. 22). 
Para o biógrafo, Clarice é a escritora, Carolina Maria de Jesus é a negra que escreveu um romance. Negra que escreveu um angustiante livro, não uma escritora. Procurado pela CULT,

\begin{abstract}
Benjamin Moser não quis dar entrevista. Ele afirmou que fez as modificações necessárias no texto para que, nas próximas edições da biografia, "suas intenções fiquem mais claras". Ele não concorda que a descrição tenha sido, de fato, preconceituosa, e afirmou que considera o assunto "fechado". (CULT, sem data).
\end{abstract}

Pondo atenção à organização de Todos os contos, outro ponto polêmico encontrado nas pesquisas de Benjamin Moser refere-se à organização do compêndio. Afirma o autor na introdução do volume:

Muita coisa nesse livro é sem precedentes. Foi a primeira vez em qualquer idioma, incluindo o português, que todos os contos de Clarice foram reunidos em um único volume. Inclui um capítulo de 'Cartas a Hermengardo' que descobri em um arquivo (MOSER, 2015, grifo nosso).

O conto referido por Benjamin Moser foi mencionado em pesquisa a respeito de crônicas por Célia Regina Ranzolin, em 1985, registrado e analisado por Aparecida Maria Nunes em estudo defendido na Universidade de São Paulo, em 1991, e incluído na íntegra pela pesquisadora no volume Clarice na cabeceira: jornalismo, em 2012. Esclarece Maria Nunes:

\footnotetext{
Há ainda, nesse volume [Clarice na cabeceira: jornalismo], crônicas e outros textos também inéditos, como a série completa de 'Cartas a Hermengardo' que o periódico Dom Casmurro publicou em 1941, textos esses que repousavam no meu arquivo desde quando iniciei o resgate dessa produção, e que agora retornam para o leitor de Clarice (NUNES, 2012, p. 18).
}

Além de se apropriar da pesquisa de Maria Aparecida Nunes, ao sugerir em um único volume todos os contos de Clarice Lispector, Moser inclui no compêndio crônicas e peça teatral da escritora. Ora, se o título do volume é Todos os contos, a incursão de textos jornalísticos e dramático na referida obra não figura coerência com a produção contista de Clarice. "Portanto", conclui Nádia Gotlib, "se o que se propõe neste volume de "todos os contos" é mesmo 
a "totalidade" dos contos, melhor seria separar logo no índice o que é do que não é do conto" (GOLTIB, 2016, p. 62)

A par de inúmeras críticas que recebeu acerca de seu posicionamento equivocado e conflitante, o biógrafo que defende "o gênero da biografia literária como uma simples interpretação"6, ao ser entrevistado pelo El País, Benjamin Moser direciona crítica acirrada ao Brasil e à Academia Brasileira: "Ler Clarice é uma experiência muito pessoal. Falar dela no código nacional ou acadêmico é uma péssima ideia, é permitir que um grupinho sem imaginação enterre uma artista em um túmulo empoeirado" (MOSER apud AVENDAÑO, 2017, s/p.).

Além de observar o tom desrespeitoso (grosseiro!) com que Moser se dirige à nação brasileira, bem como seu posicionamento em relação às produções e pesquisas nacionais acerca de Clarice Lispector, subsídios críticos que, esquece o biógrafo, serviram-Ihe de sustentação para que construísse sua Clarice, - embora usados com distorções e imprecisões, cabe ressaltar -, interessa neste ensaio a amplitude que essa mesma entrevista, concedida a Tom Avendãno, direciona ao norte americano: "Benjamin Moser, autor de Clarice, a biografia que em 2009 galvanizou a fama internacional da escritora". (AVENDÃNO, 2017, s/p.).

Ana Helena Rodrigues e Ruan Sousa Gabriel, repórteres da revista Época, ao entrevistarem Benjamin Moser, nomeiam o subtítulo da reportagem apresentando o biógrafo com o seguinte enfoque: "O escritor americano é responsável pelas novas edições da escritora brasileira em inglês e por divulgar sua obra mundo afora" (RODRIGUES; GABRIEL, 2016, s/p.). No corpo

\footnotetext{
${ }^{5}$ Registre-se o aclaramento de Nádia Battella Gotlib acerca do prólogo que Bnejamin Moser direciona ao compêndio Todos os contos: "O organizador reconhece uma relação entre a idade de Clarice e a de suas personagens, à medida que ambas passam pela adolescência, maturidade, velhice. No entanto, o repertório de personagens de Alguns contos comprova a maturidade precoce de Clarice como escritora, atenta a questões complexas do comportamento humano em todas as idades, tanto da adolescência ("Começos de uma fortuna"), como da mulher adulta ("Amor"), quanto da velhice ("Feliz aniversário"). Aliás, ao morrer com 57 anos, Clarice não experimentou as agruras das suas personagens mais velhas, octagenárias". (GOTLIB, 2016, p. 62). Sublinhe-se ainda a idade da personagem Macabéa: "ela tem dezenove anos" (LISPECTOR, 1990, p. 29).

${ }^{6} \mathrm{O}$ texto citado integra o subtítulo que o jornal El País direcionou à entrevista concedida ao periódico por Benjamin Moser: "Benjamin Moser: o culto brasileiro a Clarice Lispector embaça sua vida. Escritor americano defende o gênero da biografia literária como uma simples interpretação". No corpo do texto, a fala do biógrafo confirma a manchete dada pelo jornal espanhol: "As biografias são como a interpretação de uma peça musical. As pessoas confiam muito no retrato, mas é apenas uma maneira de contar, é a minha forma, minha história, e não a própria pessoa" (MOSER apud AGUILAR, 2017, s/p, grifos nossos).
} 
da entrevista, Moser metaforicamente confirma o que o subtítulo dado pelos repórteres evidencia: "A literatura brasileira enfrenta alguns obstáculos, pois não viaja muito. E eu resolvi comprar uma passagem para Clarice" (MOSER apud RODRIGUES, GABRIEL, 2016, s/p). Ora, a chamada da reportagem pontua algumas disparidades que urgem esclarecimentos. O subtítulo, de certa forma, iguala as produções do biógrafo à obra de Clarice Lispector: o escritor, a escritora. O posicionamento do norte-americano, inflado de pretensão, é de que sem sua interferência a obra de Clarice não teria "desembarcado" em outros continentes.

A fama internacional que Clarice Lispector goza de sua obra, sendo reconhecida como uma das principais escritoras do século $\mathrm{XX}$, longe de estar associada às produções equivocadas de Moser, se reveste, sobretudo, da própria e instigante escritura da autora. Evidente que nomes relevantes serviram de suporte para levar a literatura intimista e universal de Clarice além das fronteiras estabelecidas pelo idioma português, uma vez que sua obra, desde quando a autora era viva, se materializou em outras línguas.

Em ensaio publicado por Nádia Battela Gotlib na revista CULT, a pesquisadora cita trabalhos importantes de professores, pesquisadores, tradutores, que, ao longo dos anos, se empenharam em fazer ainda mais conhecida a poética clariciana:

E as edições se propagaram a tal ponto, [...] que, há quatro anos, a agência Carmem Balcells registrava traduções em cerca de trinta países, em línguas como o hebraico, o russo, o tcheco, o turco, o coreano, o búlgaro, o finlandês, entre tantas outras (GOTLIB, 2016, p. $62)$.

Diante de tantas "coincidências" e inúmeros "equívocos" associados às produções de Benjamin Moser, são necessárias, diferentemente do que divulga o biógrafo, concepções críticas lídimas acerca do que tem sido divulgado a respeito dos escritores brasileiros, bem como de que forma a cultura brasileira tem sido apresentada às nações. Urgem, ainda, posicionamentos críticos abalizados, a exemplo daqueles que alicerçam esta pesquisa, que refratem tamanhas improcedências. 


\section{Referências}

ABDALA JUNIOR, Benjamin. Biografia de Clarice, por Benjamin Moser: coincidências e equívocos. Estudos avançados, v. 24, n. 70, São Paulo: USP, 2010.

AGUILAR, Andrea. Benjamin Moser: "O culto brasileiro a Clarice Lispector embaça sua vida". Escritor americano defende o gênero da biografia literária como uma simples interpretação". EL PAÍS, São Paulo, 18 out. 2017.

Disponível em: https://brasil.elpais.com/brasil/2017/10/16/ cultura/1508155832_784760.html. Acesso em: 30 out. 2017.

AVENDÃNO, Tom C. Clarice Lispector em 2017: o segredo mais popular da literatura brasileira. Aos quarenta anos de sua morte, memes da autora confundem sua produção, complexa e delicada, com autoajuda. EL PAís, São Paulo, 22 set. 2017. Disponível em: https://brasil.elpais.com/brasil/2017/09/20/ cultura/1505923237_969591.html. Acesso em: 27 out. 2017.

CABALLÉ, Anna. La hipótesis judía. La biografía de Benjamin Moser explica el hermetismo de Clarice Lispector recurriendo a los orígenes hebreos de la escritora brasileña. EL PAíS, São Paulo, 22 set. 2017. Disponível em: https://elpais.com/cultura/2017/09/21/babelia/1505996394_889013.html. Acesso em: 30 out. 2017.

COUTINHO, Edilberto. Uma mulher chamada Clarice Lispector. In:

COUTINHO, Edilberto. Criaturas de papel. Rio de Janeiro; Brasília, Civilização Brasileira; INL, 1980, p. 165-170. (Publicado originalmente em O Globo, Rio de Janeiro, 29 abr. 1976).

FERREIRA, Teresa Cristina Montero. Eu sou uma pergunta: uma biografia de Clarice Lispector. Rio de Janeiro: Rocco, 1999.

GOTLIB, Nádia Battella. Clarice fotobiografia. 2. ed. São Paulo: Editora da Universidade de São Paulo, 2009b.

GOTLIB, Nádia Battella. Clarice: uma vida que se conta. 6. ed. rev. e aum. São Paulo: Editora da Universidade de São Paulo, 2009.

GOTLIB, Nádia Battella. De cuentos reunidos a Todos os contos: especialista em Clarice questiona o critério adotado em recentes edições de obras da autora. Revista CULT, São Paulo, ano 19, n. 214, jul. 2016, p. 58-63.

GOTLIB, Nádia Battella. Memória encenada: retratos, recordações, reconfigurações. In: LISPECTOR, Elisa. Retratos antigos: (esboços a serem ampliados). Org. Nádia Battella Gotlib. Belo Horizonte: Editora UFMG, 2012.

LISPECTOR, Clarice. A descoberta do mundo. Rio de Janeiro: Rocco, 1999.

LISPECTOR, Clarice. A hora da estrela. Rio de Janeiro: Francisco Alves, 1990. 
LISPECTOR, Clarice. Clarice Lispector entrevistas. Org. Claire Williams; preparação de originais e notas biográficas de Teresa Montero. Rio de Janeiro: Rocco, 2007.

LISPECTOR, Clarice. Felicidade clandestina. Rio de Janeiro: Rocco, 1998.

LISPECTOR, Elisa. No exílio. Rio de Janeiro: José Olympio, 2005.

LISPECTOR, Elisa. Retratos antigos: (esboços a serem ampliados). Org. Nádia Battella Gotlib. Belo Horizonte: Editora UFMG, 2012.

MOSER, Benjamin. A bruxaria literária de Clarice Lispector. Tradução: Paulo Migliacc. Folha de São Paulo, São Paulo, 02 ago. 2015. Disponível em: http://www1.folha.uol.com.br/ilustrissima/2015/08/1662854-a-bruxaria-literariade-clarice-lispector.shtml. Acesso em: 11 nov. 2017.

MOSER, Benjamin. Clarice, uma biografia. Tradução: José Geraldo Couto. São Paulo: Cosac Naify, 2009.

MOSER, Benjamin. Clarice, uma biografia. Tradução: José Geraldo Couto. São Paulo: Companhia das Letras, 2017.

MOSER, Benjamin. Glamour e gramática. In: LISPECTOR, Clarice. Todos os contos. Org. Benjamin Moser. Rio de Janeiro: Rocco, 2016.

NUNES, Aparecida Maria (org.). Clarice na cabeceira: jornalismo. Rio de Janeiro: Rocco, 2012.

NUNES, Aparecida Maria. Clarice Lispector jornalista: páginas femininas \& outras páginas. São Paulo: Editora Senac, 2006.

PIÑON, Nélida. Livro das horas. Rio de Janeiro: Record, 2012.

REVISTA CULT. Escritor é acusado de racismo por trecho em biografia de Clarice Lispector. s.d. Disponível em:

https://revistacult.uol.com.br/home/escritor-e-acusado-de-racismo-por-trechoem-biografia-de-clarice-lispector/. Acesso em: 27 out. 2017.

RODRIGUES, Ana Helana; GABRIEL, Ruan de Sousa. Benjamin Moser: Clarice Lispector e eu deciframos um ao outro. O escritor americano é responsável pelas novas edições da escritora brasileira em inglês e por divulgar sua obra mundo afora. Revista Época, São Paulo, 17 mai. 2016. Disponível em: http://epoca.globo.com/vida/noticia/2016/05/benjamin-moserclarice-lispector-e-eu-deciframos-um-ao-outro.html. Acesso em: 28 out. 2017.

SOUZA, Eneida Maria de. A biografia, um bem de arquivo. Alea: Estudos Neolatinos, Rio de Janeiro, v. 10, n. 1, p. 121-129, enero/jun., 2008.

WALDMAN, Berta. Entre passos e rastros: presença judaica na literatura brasileira contemporânea. São Paulo: Perspectiva, 2003. 